This item was submitted to Loughborough's Research Repository by the author.

Items in Figshare are protected by copyright, with all rights reserved, unless otherwise indicated.

\title{
The after-effects of youth unemployment: More vulnerable persons are less likely to succeed in Youth Guarantee programmes
}

\section{PLEASE CITE THE PUBLISHED VERSION}

http://dx.doi.org/10.1177/0143831X16653186

\section{PUBLISHER}

(c) The Authors. Published by Sage.

\section{VERSION}

AM (Accepted Manuscript)

\section{PUBLISHER STATEMENT}

This work is made available according to the conditions of the Creative Commons Attribution-NonCommercialNoDerivatives 4.0 International (CC BY-NC-ND 4.0) licence. Full details of this licence are available at: https://creativecommons.org/licenses/by-nc-nd/4.0/

\section{LICENCE}

CC BY-NC-ND 4.0

\section{REPOSITORY RECORD}

Selenko, Eva, and Kerstin Pils. 2016. "The After-effects of Youth Unemployment: More Vulnerable Persons Are Less Likely to Succeed in Youth Guarantee Programmes”. Loughborough University. https://hdl.handle.net/2134/22829. 
The after-effects of youth unemployment: More vulnerable persons are less likely to succeed in Youth Guarantee programs

Eva Selenko ${ }^{1}$ and Kerstin Pils ${ }^{2}$

\section{${ }^{1}$ Eva Selenko}

Loughborough University, United Kingdom

\section{${ }^{2}$ Kerstin Pils}

Jugend am Werk, Linz, Austria

\section{Corresponding author:}

Eva Selenko, School of Business and Economics, Loughborough University Loughborough, Leicestershire, LE11 3TU, United Kingdom. Phone: +44 1509228371 E-mail: e.selenko@lboro.ac.uk. 


\begin{abstract}
This article investigates unemployed adolescents' success in reemployment programs. We propose that not being in employment, education, or training indicates a setback in the achievement of important life-goals, which affects mental health and success in reemployment programs. Adolescents who are more affected by the experience of unemployment will be even less likely to succeed. An analysis of longitudinal archival records of 300 adolescents in a Youth Guarantee apprenticeship scheme confirms the expectations. Adolescents who were more vulnerable during unemployment and who had a worse relationship with their parents when starting the apprenticeship were more likely to drop out within the first year. The effect of age was moderated by relationship quality. The results show that taking the prior experience of not being in employment, education and training into account can offer a new understanding for the success of reemployment programs. Theoretical and practical implications of the findings are discussed.
\end{abstract}

Keywords: Apprenticeship, NEET, parental support, youth unemployment, Youth Guarantee. 
The after-effects of youth unemployment: More vulnerable persons are less likely to succeed in Youth Guarantee programs.

Youth unemployment is of serious concern to European societies today, as young people have been particularly badly affected by the economic recession (Papadopoulos, 2014). According to recent estimates, employment rates for young Europeans under the age of 25 fell four times as much as for the adult population. By August 2014, 7.5 million young Europeans were unemployed, not in education or training (European Commission, 2014a). Being not in employment, education or training (NEET), has a variety of severe effects on individuals, societies and the economy. Unemployment creates significant psychological and physiological distress for the individual concerned, which also has been found to have significant effects on later career success and earnings (Mroz and Savage, 2006). Also, the societal costs of young persons who are NEET are large: Reduced trust in democratic institutions, less political engagement and lower social and civic participation are just some of the presumed long-term effects. In 2011, economists estimated the costs of young people disengaging from the labour market at a staggering 153 billion Euros for the European Community (Eurofound, 2012a).

From a humanistic, societal and public policy perspective, it is hence of vital importance to keep young people in education and training- in order to curb present youth unemployment and also to heighten young peoples' future chances on the job 
market (e.g. Rumberger and Lamb, 2003). Recently, the European Union member states have adopted a so-called Youth Guarantee scheme (European Commission, 2014a), which entails various national and European Union funded measures, that offer high quality training, education, or apprenticeships to all young people under 25 who are not in education, employment and training.

What predicts the effectiveness of these programs? The presented study takes an individual-level approach to this issue. Various perspectives are possible - literature on educational dropouts would suggest to focus on individual cognitive factors (e.g. De Witte et al., 2013). Unemployment socialization literature would suggest to concentrate on the parental employment situation, as this might predict young peoples' aspirations (e.g. McLoyd, 1989). In contrast to these perspectives, the present paper will argue that being NEET will have after effects which will affect an individual's success in a Youth Guarantee Program. By drawing on life-span theory and the developmental goal perspective (Heckhausen et al., 2010), it is suggested that being not in education, employment or training would be experienced as a setback in achieving certain developmental goals. Failing to achieve a life goal has been linked to various forms of low mental health and different ways of coping (Heckhausen et al., 2010), which affect the chances to accomplish in education or training as offered by a Youth Guarantee scheme. 
Furthermore, in line with unemployment and job search research (McKee-Ryan et al., 2005; Wanberg et al., 2010) it is proposed that not finding a first job and being unemployed will be experienced differently by different people. Those who are more negatively affected by this period of unemployment and unsuccessful job search will have even fewer chances to succeed in a Youth Guarantee scheme. To provide a test of this perspective this study will analyse archived data of participants of a specific form of a Youth Guarantee program, who entered an apprenticeship program after a four month period of being not in employment, education and training. Individual background information was recorded at the onset of the program and after a year in the Youth Guarantee program a note on the individual success was made. This dataset thereby allows for an analysis of the individual level predictors of success in this specific kind of program.

The contributions of this study are manifold: First of all, this study will apply a life-span development theory perspective and combine it with findings from unemployment research, to offer a theoretically guided perspective on people who are NEET and the factors responsible for adolescent's success in Youth Guarantee programs. So far, most research on people who are NEET concentrated on establishing different profiles of people to enable a personalised service delivery (e.g. Eurofound, 2012a). This paper takes a different view by focussing on the underlying commonalities of being NEET and viewing this experience as one marked by setbacks in achieving 
developmental goals. There is substantial research available on how people cope with setbacks in the achievement of important goals (e.g. see Heckhausen et al., 2010) which can be applied for a better understanding of the NEET experience and its consequences.

Secondly, by suggesting that the factors that increase adolescents vulnerability during a period of being not in education, training or employment, also affect their success in Youth Guarantee schemes, this study allows the identification of certain risk profiles of people who might be more likely to drop out of these programs.

Lastly, by evaluating an existing Youth Guarantee program, and investigating the factors that contribute to an individual's success in it, the findings of this study might be utilised in designing a more effective service delivery of these programs. The after-effects of not being in employment, education or training

Youth Guarantee programs are new measures currently initiated in EU member states which offer employment, apprenticeships, or continued education to people under the age of 25, within 4 months of them leaving school or losing a job (European Commission, 2014a). These programs provide an opportunity for young people who are NEET to find a way "back in" to the labour market. Still, having gone through a period without employment, education or training is likely to have after-effects on young people (e.g. Mroz and Savage, 2006), which will affect their future ability to succeed in any type of program that is as offered as part of a Youth Guarantee scheme. 
There are manifold explanations for this scarring effect. Seen from a life-span development perspective, persons who were in a period of being NEET (and are hence eligible for Youth Guarantee programs) experienced obstacles in achieving one or more important developmental goal (finding a job, an apprenticeship or finishing an education) on their own. According to the theory of life span development, people's life course is marked by a set of developmental challenges or goals, which reflect cultural norms for age appropriate achievements and whose opportunities for accomplishments wax and wane over time (Heckhausen and Schulz, 1995; Heckhausen et al., 2010). Finishing an education or a training program, and finding employment are examples for such goals. Seen in that way, although people can be not in education, employment or training for a great variety of reasons (Eurofound, 2012a), most of them will have experienced some kind of obstacle in achieving an important, age-normative life goal. For example, early school leavers might have failed to achieve the developmental goal of finishing their education. People who were unable to gain employment or a traineeship would experience obstacles in the life goal of finding a first job. Adolescents, who became unemployed and cannot find reemployment, would experience setbacks in the life goal of becoming established in a career. Although the developmental deadline to compensate and still achieve these goals might not yet have passed, experiencing obstacles is likely to be perceived as stressful. People need to employ certain coping strategies to stay committed and to deal with negative side 
effects, such as negative affect, depression and an associated sense of reduced mastery and low regulatory control (Heckhausen et al., 2010). In sum, this puts people in a worse starting position for achieving future goals - they need to show regulatory control to cope with and compensate for the set back. In addition, due to being NEET they cannot practice the skills, knowledge and abilities needed to succeed later in life.

In this way, setbacks in the achievement of developmental goals are affecting the mental health and associated motivational and regulatory resources on which young people rely. People can cope with setbacks in the achievement of developmental goals in a variety of ways while remaining engaged with these goals (Heckhausen et al., 2010): They could invest additional effort and persistence in the achievement of these goals, they could to engage in self-regulatory actions to stay committed to the goal (e.g. avoid distractions; remain optimistic) or they could seek out help to compensate for the setbacks. However, people who are NEET could also attribute the setbacks to external and uncontrollable events, devalue the goal of finding employment and finishing their education, and engage in overly self-protective thoughts and behaviour, which would lead to a disengagement from these goals.

Both, withdrawal and enhanced effort might exhaust future coping resources and lead to even worse mental health (e.g. Wanberg et al., 2010). Mental health is understood to be a multidimensional construct, consisting of affective components (positive and negative affect, arousal) and behavioural components, which include a 
person's competence to deal with difficulties and a person's interest in engaging with the environment (Warr, 1990: 197). Accordingly, a good state of mental health is needed not only to cope with the adversity of being NEET but also to accomplish in a job, reemployment program or training that follow upon the period of being NEET. In order to successfully master a job or an education or a reemployment program, people need to select, engage and disengage with different goals. They need to persistently invest energy, keep themselves interested and motivated and regulate their concentration, by exerting control over their external environment as well as over their own behaviours and resources (Heckhausen et al., 2010). Persons in a state of low mental health which accompanies the setback in life goals, tend to be in a dysphoric depressive mood, a low sense of competence and low aspirations and are consequently less able to successfully master Youth Guarantee programs.

Low age, socioeconomic status and relationship quality with the parents as risk factors While experiencing setbacks in the achievement of developmental goals, and a period of unemployment ${ }^{1}$ and job search is going to put probably every young person's regulatory abilities and mental health under strain, individuals who are disproportionally affected during that period are likely to be even worse off.

\footnotetext{
${ }^{1}$ Unemployment in this study is defined in line with the International Labour Organisation's (2013: 10) as a situation concerning people who are "not in employment, carried out activities to seek employment during a specified recent period" and are “currently available to take up employment given a job opportunity”.
} 
Not everyone is equally affected by unemployment. According to metaanalytical results from unemployment research (McKee-Ryan et al., 2005; Paul and Moser, 2009) there are certain risk factors, that can enhance the negative effect of unemployment on individuals. Particularly, young age, financial resources, and social support matter significantly for the experience of being not employed, in education or in training.

Up until midlife, age is positively related with well-being among unemployed persons: Younger unemployed persons report less wellbeing than middle-aged persons (Paul and Moser, 2009). Consequently, younger adolescents will probably be more affected than older adolescents when they are not employed and searching for a job. Younger people might also possess fewer regulatory abilities to start with, as those are partly determined by age (e.g. Heckhausen and Schulz, 1995). If chronological age is used as a rough estimator of an adolescent's development, younger adolescents might have less experience with coping with stressful events and hence possess less varied coping responses (e.g. Compas et al., 2001). In sum, this puts younger adolescents at a greater risk during a period of being not employed, which will consequentially reduce their abilities to perform well in a Youth Guarantee program. Hypothesis 1 hence states: Persons who are younger at the onset of the Youth Guarantee Program, are more likely to drop out (H1). 
Also, people who experience financial hardship report worse wellbeing during unemployment and are more affected by setbacks in the job search process (McKeeRyan, et al., 2005; Wanberg et al., 2010). Transferred to the present analysis this suggests that young persons who are socioeconomically worse off, will be more affected by being not employed and searching for jobs, which will leave them more exhausted and consequently reduce their chances to succeed in a Youth Guarantee program. Socioeconomic status of young people is often operationalised by their parents’ occupational status, education, and employment status (De Witte et al., 2013). Young people whose parents are unemployed while they themselves are not in employment and searching for a job, are probably experiencing more financial hardship, which could aggravate the effect of their own NEET spell. This is likely to leave them more exhausted and with lower chances to succeed in a reemployment program. Hypothesis 2 hence proposes that persons who come from lower socioeconomic backgrounds will be more likely to drop out of a Youth Guarantee program (H2).

There is a plethora of evidence showing that having enough instrumental and emotional support through social interactions has a positive effect on wellbeing during unemployment (see McKee-Ryan et al., 2005 for an overview). One of the most central sources of social support for young people is their parents. There is multinational evidence on youth unemployment that shows that young people are less negatively affected by unemployment if they can count on emotional support from their parents 
(Bjarnason and Sigurdardottir, 2003). Consequently, young people will handle a period of being NEET better if they have a good relationship with their parents. A good relationship with the parents, especially in the form of receiving warmth and appreciation also matters for educational attainment (Blondal and Adalbjarnardottir 2009; Dietrich and Salmela-Aro, 2013) and has even been labelled the "single most significant family factor scholars agreed upon” in that regard (p. 21, De Witte et al., 2013). In short, having a better quality relationship with the parents is likely to leave people less mentally exhausted and with better regulatory abilities after a NEET spell. Consequently, Hypothesis 3 (H3) states: Persons who report a better quality relationship with their parents at the onset of a Youth Guarantee program, will be less likely to drop out.

The moderating effect of having a good relationship with the parents

The relationship young people have with their parents is likely to not only influence their well-being and associated regulatory abilities during their NEET spell, but it might also alleviate the impact of other risk factors. In comparison to other social institutions (e.g. peers and friends), parents act as the most significant source of support during adolescence. Social support from parents in times of being NEET could ease the emotional strain of failing to achieve a life goal, as well as assist with the development of alternative coping strategies. Also, having a dissatisfactory relationship with their own parents is considered to be the best indicator for emotional problems among 
adolescents (Helsen et al., 2000). Having a good relationship with parents might hence moderate the impact of young age and low socioeconomic status on the experience of unemployment and job search. This has been found by Bjarnason and Sigurdardottir (2003), who report that a warm relationship with parents can buffer the negative effect of financial deprivation during unemployment. Consequently, a good relationship with parents would limit the impact of other risk factors on dropout from Youth Guarantee programs. This leads to the following hypothesis: The quality of the relationship with their parents will reduce the effect of age and socioeconomic status on dropout. Younger persons and persons from lower socio economic background, will drop out less frequently of a Youth Guarantee program if they have a better relationship with their parents, than if they have a worse relationship with their parents (H4). Figure 1 illustrates the model investigated in the present study as well as the proposed conceptual mechanisms. It is important to note that this study focusses on the factors affecting a young person's mental health at the start of a Youth Guarantee program and dropout a year later only. Environmental and training related factors within the first year of Youth Guarantee that contribute to the likelihood of dropout are not included.

FIGURE 1 here 


\section{The present study}

The present study analysed archival data from a particular form of Youth Guarantee program (“Training Guarantee”), initiated by the Austrian state. Participants of these programs are adolescents who finished compulsory education, but did not manage to either continue into higher education or land an apprenticeship on their own within four months following them ending their schooling. Hence, they had experienced a four month period of being NEET. In Austria, Youth Guarantee programs are arranged by state-funded vocational institutions which organise apprenticeships in supra-company workshops, or within a wider network of companies. Youth Guarantee apprenticeships and the educational degree they provide are equal to company-based apprenticeships (see; Austrian Federal Ministry of Labour, Social Affairs and Consumer Protection, 2014; European Commission, 2014b). At the onset of the Youth Guarantee program, an elaborate intake interview is conducted and a personal record is created for each participant. This record includes an assessment of the person's personal background, their family situation, and their cognitive abilities and skills, and is updated each year with information on the participant's progress in the program. These records were used for analysis in the present study. Most dropouts occur in the first year of the two year program, which is why this research focussed on the first year outcomes only. 
Programs like the one described have been in place in Austria and Finland for a couple of years and are regarded as being highly successful in curbing youth unemployment (e.g. Eurofound, 2012b). They have acted as role-models that informed the EU's Youth Guarantee initiative, to which all EU member states have recently committed (European Union, 2013; European Commission, 2014c). Despite their positive image, systematic results on the success rate of these programs are not yet available. A recent review by Eurofound reveals that although Youth Guarantee programs manage to reengage most of their participants with the labour market, dropout rates can still be as high as 30\% (Eurofound, 2012a). There are no studies available to our knowledge that look at the background and experiences of the individual participants of these programs and the factors that predict when they will succeed. European-wide evaluations of the Youth Guarantee have been planned for December 2015 and 2018, but are not publically available at the time of writing (European Commission, 2015). The present study will highlight some of the factors that contribute to dropouts of Youth Guarantee programs and might help with the planning of future evaluations. 


\section{Method}

\section{Procedure and background}

The second author was granted access to the personal records of participants of a statefunded apprenticeship program from an Austrian vocational institution. For this study, 300 reports were randomly selected from the archive, of participants who started the program between the years 2007 and 2011. The only selection criterion was a quota sampling on gender (50\%). All reports were anonymised before being coded into an SPSS data file.

Sample description and measures

The selected reports were of people who were on average 16.67 years of age (SD $=1.14)$ at that time. Most of them (64\%) were migrants but had spent the largest part of their lives in Austria ( $M=11.95, S D=5.89$ years). As for schooling, $18 \%$ finished a special school, 81\% finished a secondary modern school, 3 persons attended a high school before entering the program. For those who attended the latter two schools, 25\% failed their final exams. The records also provided information regarding where the apprentices lived. The majority (74.7\%) lived with two parents, $19.3 \%$ lived in a single parent household, $4 \%$ lived outside home (either on their own or in a state-care foster home), six persons indicated "elsewhere" as their living situation (and were hence excluded from further analysis). On average, persons had 2.32 siblings ( $S D=1.44)$. The records also included a measurement of cognitive abilities measured by a short version 
of the German "Wilde-intelligence test” (Kersting et al., 2008). We decided to include this variable as a control factor into our analysis, as cognitive abilities are regarded as an established predictor of vocational achievement (Park et al., 2007) and individual training motivation and training outcomes in a wide variety of studies (Colquitt et al., 2000). The Wilde intelligence test contains six sub dimensions: verbal, mathematical, logical, and spatial abilities, perception speed and precision, and memory. The respondents' scores on each of these sub dimension were categorised on a 7-point scale ( 1 = far below average, 7 = far above average) by the administrating psychologist of the institution. An exploratory factor analysis across these six sub-dimensions with an Eigenvalue extraction $>1$ revealed a single factor solution that accounted for $48.37 \%$ of all variance. Taking these six subscales together revealed an internal consistency of Cronbach alpha $=0.77$. There were a couple of missing values on these scales, further reducing the sample to be used for analysis to $n=255$.

Socioeconomic status. In research on early school leavers, socioeconomic status is often operationalised via the employment status of the parents (De Witte et al., 2013). Of those records where employment data of the parents was available, most (82.6\%) of all fathers were employed, as compared to $59.6 \%$ of all mothers. There appeared to be a lot $(25.9 \%)$ of missing data on the employment status of the parents, which necessitated a closer look. Maybe unsurprisingly, the missing data was associated with the living situation of the apprentice: If a person lived in a single parent household missing values 
of the employment status of their other parent were more common; if they lived in foster care homes often the employment status of both of their parents was missing. In order to not lose these respondents from the analysis, missing data on the employment status variable was dummy-coded and included in the analysis.

The perceived relationship quality with the parents was measured at the second or third meeting of the intake period, as soon as there was enough trust established between the personal advisor and the apprentice to have an open conversation about this topic. Participants were asked to reflect on what the situation at home was like for them and how well they got along with their parents. The conversation ended with asking the apprentices to rate their relationship with their parents according to school-grades (1= very good, 5 = fail). For the present analysis these scores were recoded so that high numbers represent a good relationship quality.

Dropout. At the end of the first year, the personal advisor made a comment on the participants' continuation in the apprenticeship. Participants could drop out of the program for various reasons: they could be suspended from the course (e.g. due to insufficient attendance or behavioural issues) (23.6\%) or they exit voluntarily (15.2\%). People could also end the program out of positive reasons, because they managed to find an apprenticeship outside the Youth Guarantee program (23.0\%) or because they found employment in a low-level job (6.1\%). 23.6\% finished the program and continued on to the next year, $8.4 \%$ joined another course. Since this study was interested in 
premature unsuccessful termination of these apprenticeships all those persons who were either suspended or who quit voluntarily were coded as dropouts (38.85\%) while all the others were coded as successful cases.

\section{Results}

A Pearson correlation of the variables of interest showed that younger people, people of foreign nationality, and those who reported a lower relationship quality with their parents also dropped out more frequently. None of the other demographic variables or the socioeconomic status (as indicated by the employment status of the parents) correlated with dropout after the first year (see Table 1 for details).

TABLE 1 here

To test the hypotheses and investigate the independent impact of age, socioeconomic status and relationship quality, a hierarchical logistic regression analysis was carried out, following the suggestions by Jaccard (2001). All continuous variables were z-standardised before entering the analysis; interaction terms were calculated on basis of z-standardized values.

First, the control variables gender, nationality, cognitive abilities, number of siblings, living in a single parent household, living alone, and school type were entered. 
None of these variables significantly added to the explanation of dropout, $C h i^{2}(7)=$ $8.50, p=.291$.

TABLE 2 here

Next, age, socioeconomic status (as indicated by the employment status of the parents) and relationship quality were added to the prediction. This increased the explained variance of dropout to $26 \%$, Nagelkerke $R^{2}=.262, \Delta C h i^{2}(6)=45.98, p<$ .001. Age and relationship quality had a significant impact as expected, people who were younger at the onset of the program and people who reported a worse relationship quality with their parents were more likely to drop out, which supports Hypotheses 1 and 3 (see Table 2). Employment status of the parents did not add to the prediction of dropout, thus not supporting Hypothesis 2.

The third step tested for the moderation effect of relationship quality on the effect of age and employment status. Since employment status did not have an independent effect on its own, this interaction effect was not estimated. Instead, only the interaction term that tests the moderating effect of relationship quality on the effect of age was included. This increased the explanation of dropout to $27.9 \%, \Delta C h i^{2}(1)=4.07$, $p=.044$ 
FIGURE 2 here

Plotting the two way interaction onto the probability to drop out shows that age only matters for dropout if the relationship quality is high; in this case people tend to drop out less when they get older (see Figure 2). If the relationship quality is low, people drop out more, relatively independent of their age. This is slightly different to what was expected. Hypothesis 4 presumed that relationship quality would reduce the negative effect of low age, which is the opposite of what was found.

It needs to be noted that dropout in this study was defined as occurring when someone either got suspended or quit voluntarily. "Not dropping out” consisted of behaviours as varied as either finishing the first year of the course, getting onto another course, finding an apprenticeship outside the Youth Guarantee institution, or finding employment in a low-level job. These are rather different kind of outcomes and it is likely that by re-categorising them into only one category (“not dropping out”), a considerable amount of variance was lost. To test for the robustness of our findings and explore whether different variables would be differently responsible for the six possible outcomes of the program, one-way ANOVAs and $\mathrm{Chi}^{2}$ tests were carried out, each using exit reasons as an independent variable (see Table 3 for a comparison of means and probabilities). There were significant differences between the groups on age, 
$F(5,295)=3.11, p=.009$, relationship quality, $F(5,295)=10.67, p<.001$, number of siblings, $F(5,295)=2.45, p=.050$ and on nationality $C h i^{2}(5)=16.36, p=.006$. All other variables (cognitive ability, gender, living alone, going to a special school, living in a single parent household, all parental employment categories) did not make a difference for the individual exit reason.

Please insert Table 3 about here

A post-hoc comparison of the individual five groups showed that people who were suspended had a significantly lower relationship quality with their parents than all other groups (except for those who quit voluntarily) and were significantly younger than those who quit voluntarily and those who changed onto another course program. People who finished the program successfully had the smallest number of siblings and were more likely to be Austrian nationals than others (except for those who found an apprenticeship on their own)

These two additional factors - number of siblings (which could be seen as a proxy for socioeconomic status) and minority status - are also established moderators of the unemployment experience (Paul and Moser, 2009). Therefore this indicates additional support for the assumption that factors that influence adolescents' 
vulnerability during unemployment also affect their chances in Youth Guarantee programs. What follows from these findings will be explored in detail in the next section.

\section{Discussion}

The presented study aimed to predict adolescents' chances to succeed in an apprenticeship program after they went through a period of being NEET. Embedded in a life-span theory perspective (Heckhausen et al., 2010) and by drawing on results from unemployment research (McKee-Ryan et al., 2005; Paul and Moser, 2009; Wanberg et al., 2010), it was proposed that the experience of being not in employment, education and training is likely to have affected young peoples’ affective and behavioural resources needed for future educational attainment. It was further proposed that, younger people, people from lower socioeconomic backgrounds, and those who had a worse relationship with their parents, would have an even more negative experience while being NEET, resulting in a lower likelihood to finish a Youth Guarantee program. Furthermore, it was assumed that a good relationship with the parents could act as an extra safety net, if people were of higher risk because of young age or low socioeconomic status.

Our findings are largely supportive of this perspective. Age was found to be an important predictor for finishing an apprenticeship in a Youth Guarantee scheme. Younger people were significantly more likely to drop out of the apprenticeship 
program than people who finished the apprenticeship, found a job, found an apprenticeship outside the program, or continued onto another program. Given that age is positively related to wellbeing among young unemployed people (e.g. Paul and Moser, 2009), this could indicate that younger people were more affected by being NEET in their mental health and consequently less able to self-regulate and cope with the demands of an apprenticeship (Heckhausen, 2010). There was also a strong effect of relationship quality, people who reported a worse relationship quality with their parents at the onset of the program, were less likely to finish the program. This is in line with previous studies which illustrate the importance of social support for young people’s coping with unemployment (e.g. Bjarnason and Sigurdardottir, 2003; McKee-Ryan et al., 2005). It is also reflected in studies on the role of parental support for academic aspirations (e.g. Duchesne and Larose, 2007; Tynkkynen et al., 2010) and the role of parental warmth in particular (Dietrich and Salmela-Aro, 2013).

Relationship quality also moderated the effect of age, but this effect was rather small and in a different manner than expected. Young people had a slightly higher chance for dropout than older people, but only if the relationship quality was high. If the relationship quality was low, age did not matter anymore for dropout. Apparently, the effect of relationship quality over-shadowed the effect of age - if the relationship quality was good then there was a relationship between age and drop out, if it was bad, 
then there was none. Most people in this sample reported a good relationship with their parents, which might also explain why on average there was a significant effect of age.

The findings regarding socioeconomic background are less clear. If only the parental employment situation is regarded as an indicator for socioeconomic status, then there was no relationship with dropout. Probably though, as a sole indicator, employment status of the parents might have been too narrow. There is no unified definition of socioeconomic status, but authors typically agree that it is captured by combining multiple indicators together (e.g. occupation but also education, income etc.) (Bradley and Corwyn, 2002). If, for example, also "number of siblings” is included as an indicator of poverty and low socioeconomic status, then there would be some support for this hypothesis, as people with more siblings were less likely to succeed in the program. Future research would certainly need to include more measures of socio economic status to allow for a better test of this influence. If supported, the nonsignificant influence might even covey a kind of hopeful message - while socioeconomic background might be a risk factor to fall into a NEET spell (e.g. Bynner and Parsons, 2002), it does not necessarily affect young peoples’ future likelihood to escape this situation.

In sum, the effects found in this study fit well within the developmental goal and mental health perspective. The same factors that influence vulnerable adolescents' mental health during a period of setbacks in the achievement of life goals, also affect 
their likelihood to succeed in a Youth Guarantee program. Presumably, young people who are more strongly affected by being NEET, experience even more depressive mood, less self-efficacy and less self-esteem than their peers. They might lose their interest in further education and their competence in dealing with education and daily difficulties. This, eventually, will put them at a worse starting position in a Youth Guarantee program. Also, the unexpected effect of nationality can be explained in that way: Minority status has been related to poorer well-being among unemployed persons (Paul and Moser, 2009), as it is assumed to contribute to an accumulation of stress factors. Similarly, young people who come from a minority background and are NEET might be more affected than their colleagues who are from the majority, who could have exhausted their coping abilities which they later need for handling the demands of Youth Guarantee programs.

More support for the assumption that it's the being NEET experience which puts adolescents at risk for their future educational success can also be seen in the nonsignificant role of other predictors. Cognitive abilities, for example, which would be a typical predictor of school dropout (e.g. de Witte et al., 2013), or the unemployment status of the parents, which would play a role according to a socialisation perspective (e.g. McLoyd, 1989) did not matter here. This indicates that the factors predicting dropout from a Youth Guarantee program differ slightly from those predicting dropout from general education. Instead, factors that are moderators of the unemployment 
experience played a role. This might indicate fundamental differences between school dropout and Youth Guarantee program dropout. More knowledge on apprenticeship dropout, or dropout from institutions other than schools would be needed to explore this issue.

Certainly, this study does not come without limitations as it illuminates only the cornerstones of a process wherein multiple factors play a role. One of the drawbacks is the absence of evidence on well-being, depressed mood or competence in this data collection. In that way, we cannot be fully certain that it is reduced mental health that connects vulnerable NEET groups with dropout, although literature strongly suggests it is. Future research could include measures of mental health, as well as information on the experience of the NEET spell to allow for a test of the explanatory potential and limits of the proposed model. Secondly, our explanation focusses on the unemployment experience of adolescents before they enter the Youth Guarantee program and takes that as an explanation for later dropout. It does not pay tribute to the great variety of experiences young people have while in the program, which play an essential role and link the starting position adolescents have to later dropout. Also, our analysis did not include structural and social aspects that could be of relevance (e.g. institutional support). Lastly, despite the empirical and theoretical support for the suggested framework, alternative explanations can not be ruled out. For instance, younger age and lower relationship quality with the parents might both be influenced by a third factor. 
Both could indicate a yet incomplete social skills or coping abilities development, which is essential for academic achievement (e.g. Compas et al., 2001; Malecki and Elliott, 2002; McClelland et al., 2000). Not having sufficient social skills might affect the relationship with the parents at home as well as the behaviour at the apprenticeship training institution (reflected in people getting suspended or quitting more easily). To confirm the causality of the proposed effects, longitudinal replication studies, which control for measures of social skills, would be needed.

In sum, we believe that the dynamic perspective provided by including the affective and behavioural consequences of being NEET into the framework offers a unique empirical and theoretical contribution to the literature on youth unemployment and reemployment. Most studies so far have provided a rather static view by looking at the attributes of individual job seekers, their social environment or the structural and labour market measures in place. Theoretically driven explorations in the field are rare and so are studies that acknowledge the interdependence of the experiences (and go beyond using "unemployment duration” as a control). The results of this study show that moderators of failed goal achievement (in the form of previous experience of unemployment and unsuccessful job search) are likely to influence future achievements as well: All aspects that predicted dropout from the program under study are also wellestablished influences of the mental health, well-being and regulatory abilities of unemployed people. This perspective on youth reemployment can assist future research 
(1) in systematically investigating the role of moderators of the unemployment experience as predictors of dropout of reemployment programs, (2) in exploring whether factors beneficial to the affective and behavioural components of mental health might increase the chance to finish a Youth Guarantee program, and (3) in identifying people at particular risk from being more affected by NEET spells than others.

Aside from their theoretical implications, the findings of the present study might also be of interest to practitioners and youth councillors offering training under the recently ratified Youth Guarantee scheme. Our study shows that being out of employment, education and training is very likely to "leave scars". It seems that people who are likely to have suffered more while they were NEET, might need an extra boost to their well-being and regulatory abilities, in order to be able succeed in reemployment programs. Fostering young people’s resources of social support, for example by improving their private relationship with their parents might be one way to achieve that. Counselling them for depressive affect might be another. Also, policy makers and public funding institutions might benefit from the findings of this study, when deciding which particular Youth Guarantee scheme to implement and support. We cautiously conclude that programs that pay attention to young people's previous NEET experience and their private situation at home, might be more effective than others. 


\section{Author biographies}

Dr Eva Selenko is a lecturer at the Institute of Work Psychology, Sheffield, UK. Her research focusses on the meaning of work, unemployment and job insecurity for individual well-being. With her research she hopes to add to a better understanding of the psychological consequences of marginalised employment.

Mag Kerstin Pils is head of the 'Vocational Training Assistance' section for Youth at Work, Austria (part of BBRZ GROUP). With many years of experience in supporting young adults with impairments, she is keen on developing new approaches and methods to tackle the special needs of young people with disabilities. 


\section{References}

Austrian Federal Ministry of Labour, Social Affairs and Consumer Protection, (2014) Youth Guarantee Implementation Plan Austria. Available at: http://ec.europa.eu/social/main.jsp?catId=1090\&langId=en

Bjarnason T and Sigurdardottir TJ (2003) Psychological distress during unemployment and beyond: social support and material deprivation among youth in six northern European countries. Social Science and Medicine, 56, 973-985.

Blondal K and Abdalbjarnardottir S (2009) Parenting practices and school dropout: a longitudinal study. Adolescence, 44, 729-749.

Bradley RH and Corwyn RF (2002) Socioeconomic status and child development. Annual Review of Psychology, 53, 371-399.

Bynner J and Parsons S (2002) Social exclusion and the transition from school to work:

The case of young people not in education, employment, or training (NEET) Journal of Vocational Behavior, 60, 289-309.

Colquitt JA, LePine JA and Noe RA (2000) Toward an integrative theory of training motivation: A meta-analytic path analysis of 20 years of research. Journal of Applied Psychology, 85, 678-707. 
Compas BE, Connor-Smith JK, Saltzman H, et al.(2001) Coping with stress during childhood and adolescence: Problems, progress and potential in theory and research. Psychological Bulletin, 127, 87-127.

De Witte K, Cabus S, Thyssen G, et al. (2013) A critical review of the literature on school drop out. Educational Research Review, 10, 13-28.

Dietrich J and Salmela-Aro K (2013) Parental involvement and adolescent's career goal pursuit during the post-school transition. Journal of Adolescence, 36, 121-128.

Duchesne S and Larose S (2007) Adolescent parental attachment and academic motivation and performance in early adolescence. Journal of Applied Social Psychology, 37, 1501-1521.

Eurofound (2012a) NEETs - Young people not in employment, education or training: Characteristics, costs and policy responses in Europe. Publications Office of the European Union, Luxembourg.

Eurofound (2012b) Youth Guarantee: Experiences from Finland and Sweden. European Foundation for the Improvement of Living and Working Conditions. Available at:

http://eurofound.europa.eu/sites/default/files/ef_files/pubdocs/2012/42/en/1/EF1 242EN.pdf 
European Commission (2014a) Memo. The EU Youth Guarantee. Available at: http://europa.eu/rapid/press-release_MEMO-14-571_en.htm

European Commission (2014b) National Youth Guarantee Action Plans. Available at: http://ec.europa.eu/social/main.jsp?catId=1090andlangId=en

European Commission (2014c) Youth Guarantee: learning from the Finnish experience. Press release. IP/14/1018. Available at: http://europa.eu/rapid/press-release_IP-14-1018_en.htm

European Commission (2015) Guidance on evaluation of the youth employment initiative. Available at: ec.europa.eu/social/BlobServlet?docId=13458andlangId=en

European Union (2013) Official Journal of the European Union. Information and Notices, vol. 56, 26 April 2013. Available at: http://eur-lex.europa.eu/legal-content/EN/ALL/?uri=OJ:C:2013:342:TOC

Heckhausen J and Schulz R (1995) A life-span theory of control. Psychological Review, 102, 284-304.

Heckhausen J and Tomasik MJ (2002) Get an apprenticeship before school is out: How German adolescents adjust vocational aspirations when getting close to a developmental deadline. Journal of Vocational Behavior, 60, 199-219.

Heckhausen J, Wrosch C and Schulz R (2010) A motivational theory of life-span development. Psychological Review, 117, 32-60. 
Helsen M, Vollebergh W and Meeus W (2000) Social support from parents and friends and emotional problems in adolescence. Journal of Youth and Adolescence, 29, 319-335.

Hobfoll SE (2001) The influence of culture, community, and the nested-self in the stress process: advancing conservation of resources theory. Applied Psychology: An International Review, 50, 337-421.

International Labour Organisation (2013) Resolution I: Resolution concerning statistics of work, employment and labour underutilization. Adopted by the Nineteenth Conference of Labour Statisticians (October 2013). Available at: http://www.ilo.org/global/statistics-and-databases/standards-andguidelines/resolutions-adopted-by-international-conferences-of-labourstatisticians/WCMS_087481/lang--en/index.htm

Jaccard J (2001) Interaction effects in logistic regression. Sage University Paper Series: Quantitative Applications in the Social Sciences. Thousand Oaks: Sage.

Kersting M, Althoff K and Jaeger AO (2008) Wilde-Intelligenz-Test2 (WIT-2) [Wildeintelligence test, $2^{\text {nd }}$ revision] Manual. Göttingen: Hogrefe.

Malecki CK and Elliott SN (2002) Children’s social behaviors as predictors of academic achievement: A longitudinal analysis. School Psychology Quarterly, $17,1-23$. 
McClelland MM, Morrison FJ and Holmes DL (2000) Children at risk for early academic problems: The role of learning-related social skills. Early Childhood Research Quarterly, 15, 307-329.

McKee-Ryan FM, Song Z, Wanberg CR, et al. (2005) Psychological and physical wellbeing during unemployment: A meta-analytic study. Journal of Applied Psychology, 90, 53-76.

McLoyd VC (1989) Socialization and development in a changing economy. The effect of parental job loss and income loss on children. American Psychologist, 44, 293-302.

Mroz TA and Savage TH (2006) The longterm effects of youth unemployment. The Journal of Human Resources, 41, 259-293.

Park G, Lubinski D and Benbow CP (2007) Contrasting intellectual patterns predict creativity in the arts and sciences. Psychological Science, 18, 948-952.

Paul KI and Moser K (2009) Unemployment impairs mental health: Meta-analyses. Journal of Vocational Behavior, 74, 264-282.

Papadopoulos O (2014) Youth unemployment discourses in Greece and Ireland before and during the economic crisis: Moving from divergence to 'contingent convergence’. Economic and Industrial Democracy, online first, 1-23, DOI: $10.1177 / 0143831 X 14550694$ 
Poulin MJ and Heckhausen J (2007) Stressful events compromise control strivings during a major life transition. Motivation and Emotion, 31, 300-311.

Rumberger RW and Lamb SP (2003) The early development and further education experiences of high school dropouts: a comparative study of the United States and Australia. Economics of Education Review, 22, 353-366.

Tynkkynen L, Nurmi JE and Salmela-Aro K (2010) Career goal-related social ties during two educational transitions: Antecedents and consequences. Journal of Vocational Behavior, 76, 448-457.

Wanberg CR, Zhu J and Van Hooft EAJ (2010) The job search grind: Perceived progress, self-reactions, and self-regulation of search effort. Academy of Management Journal, 53, 788-807.

Warr P (1990) The measurement of well-being and other aspects of mental health. Journal of Occupational Psychology, 63, 193-210.

Westin S, Schlesselman JJ and Korper M (1989) Long-term effects of a factory closure: Unemployment and disability during ten years’ follow up. Journal of Clinical Epidemiology, 42, 435-441. 


\section{Table 1}

Pearson Correlation of Dropout with Age, Cognitive Ability and Relationship Quality $(n=255)$.

\begin{tabular}{|c|c|c|c|c|c|c|c|c|c|c|c|c|c|c|c|}
\hline & $\mathrm{M}$ & SD & 1 & 2 & 3 & 4 & 5 & 6 & 7 & 8 & 9 & 10 & 11 & 12 & 13 \\
\hline 1. $\quad$ Age & 16.63 & 1.16 & - & & & & & & & & & & & & \\
\hline 3. Nationality & 0.27 & 0.45 & -.00 & -.02 & - & & & & & & & & & & \\
\hline 5. Single parent & 0.18 & 0.38 & -.08 & .02 & .08 & $-.15^{*}$ & - & & & & & & & & \\
\hline 6. Lives alone & 0.05 & 0.21 & .12 & .00 & .05 & .02 & -.10 & - & & & & & & & \\
\hline 7. Special school & 0.19 & 0.39 & .06 & .07 & .00 & .02 & .04 & $.13^{*}$ & - & & & & & & \\
\hline 10. Mother emplD1 & 0.38 & 0.49 & .01 & .11 & -.12 & $.27^{* *}$ & -.10 & -.10 & .08 & .10 & -.09 & - & & & \\
\hline 11. Mother emplD2 & 0.05 & 0.23 & -.04 & -.06 & $.15^{*}$ & -.01 & $.25^{* *}$ & $.35^{* *}$ & .06 & -.05 & .11 & $-.19^{* *}$ & - & & \\
\hline 12. Cognitive abilities & 3.14 & 0.79 & $-.24^{* *}$ & $.16^{* *}$ & $.19^{* *}$ & -.11 & $.17^{* *}$ & -.04 & $-.25^{* *}$ & -.11 & $.14^{*}$ & $-.14^{*}$ & .08 & - & \\
\hline $\begin{array}{l}\text { 13. Relationship } \\
\text { quality }\end{array}$ & 4.16 & 1.05 & .03 & .06 & -.06 & .00 & .04 & $-.26^{* *}$ & -.11 & -.04 & -.02 & .02 & -.10 & -.08 & - \\
\hline 14. Dropout & 0.38 & 0.49 & $-.16^{*}$ & -.01 & $-.15^{*}$ & .01 & .02 & .05 & .08 & .03 & .07 & .09 & -.01 & -.06 & $-.35^{* *}$ \\
\hline
\end{tabular}

Note. Gender: 1 = male; nationality: $1=$ Austrian, $0=$ non-Austrian; single parent: 1 = living with single parent, $0=$ living with two parents; lives alone (1)/does not (0) live alone or in state care foster homes; father and mother employment: D1 = unemployed(1) or not(0), D2 = unknown employment (1) or not (0); special school: $\operatorname{did}(1) / \operatorname{did}$ not (0) attended a school for learning disabilities

${ }^{*} p<.05,{ }^{* *} p<.01$. 
Table 2

Logistic Regression Analysis Results for the Prediction of Dropout by Control Variables, Age, Socioeconomic Status and Relationship with Parents $(n=255)$.

\begin{tabular}{|c|c|c|c|c|c|}
\hline \multicolumn{6}{|c|}{$\begin{array}{r}\text { OR } \\
\text { Step } 1 \\
\end{array}$} \\
\hline Gender & $-0.04(0.27)$ & 0.96 & {$[0.57 ; 1.63]$} & 0.02 & .876 \\
\hline Nationality & $-0.72(0.30)$ & 2.05 & {$[1.14 ; 3.67]$} & 5.78 & .016 \\
\hline Cognitive abilities & $-0.04(0.14)$ & 0.96 & {$[0.73 ; 1.27]$} & 0.07 & .789 \\
\hline Special school & $0.35(0.35)$ & 1.41 & {$[0.72 ; 2.79]$} & 1.00 & .317 \\
\hline Nr. of siblings & $-0.03(0.14)$ & 0.97 & {$[0.73 ; 1.27]$} & 0.06 & .810 \\
\hline Single parent household & $0.20(0.35)$ & 1.22 & {$[0.61 ; 2.43]$} & 0.31 & .581 \\
\hline Lives alone & $0.56(0.61)$ & 1.75 & {$[0.53 ; 5.76]$} & 0.84 & .358 \\
\hline \multicolumn{6}{|c|}{$\begin{array}{r}\text { Step } 2 \\
\end{array}$} \\
\hline Gender & $0.04(0.30)$ & 1.04 & {$[0.58 ; 1.89]$} & 0.02 & .893 \\
\hline Nationality & $-0.84(0.33)$ & 2.32 & {$[1.21 ; 4.46]$} & 6.40 & .011 \\
\hline Cognitive abilities & $-0.25(0.16)$ & 0.78 & {$[0.57 ; 1.07]$} & 2.37 & .123 \\
\hline Special school & $0.14(0.39)$ & 1.15 & {$[0.54 ; 2.46]$} & 0.12 & .725 \\
\hline Nr. of siblings & $-0.02(0.16)$ & 0.98 & {$[0.71 ; 1.34]$} & 0.02 & .884 \\
\hline Single parent household & $-0.38(0.69)$ & 0.68 & {$[0.18 ; 2.66]$} & 0.30 & .584 \\
\hline Lives alone & $-0.73(0.98)$ & 0.48 & {$[0.07 ; 3.25]$} & 0.56 & .453 \\
\hline Age & $-0.43(0.16)$ & 0.65 & {$[0.48 ; 0.89]$} & 7.23 & .007 \\
\hline Employment father & & & & 2.10 & .350 \\
\hline Employment mother & & & & 1.42 & .491 \\
\hline Relationship w. parents & $-0.89(0.16)$ & 0.41 & {$[0.30 ; 0.57]$} & 29.36 & .000 \\
\hline \multicolumn{6}{|c|}{ Step 3} \\
\hline Gender & $0.03(0.30)$ & 1.03 & {$[0.57 ; 1.86]$} & 0.01 & .932 \\
\hline Nationality & $-0.81(0.34)$ & 2.25 & {$[1.16 ; 4.35]$} & 5.75 & .016 \\
\hline Cognitive abilities & $-0.30(0.17)$ & 0.74 & {$[0.53 ; 1.02]$} & 3.28 & .070 \\
\hline Special school & $0.10(0.39)$ & 1.11 & {$[0.51 ; 2.38]$} & 0.07 & .797 \\
\hline Nr. of siblings & $0.02(0.16)$ & 1.02 & {$[0.74 ; 1.40]$} & 0.01 & .913 \\
\hline Single parent household & $-0.59(0.71)$ & 0.55 & {$[0.14 ; 2.23]$} & 0.70 & .404 \\
\hline Lives alone & $-1.42(1.09)$ & 0.24 & {$[0.03 ; 2.02]$} & 1.72 & .190 \\
\hline Age & $-0.51(0.17)$ & 0.60 & {$[0.43 ; 0.84]$} & 8.77 & .003 \\
\hline Employment father & & & & 2.88 & .237 \\
\hline Employment mother & & & & 1.51 & .470 \\
\hline Relationship w. parents & $-0.95(0.17)$ & 0.39 & {$[0.28 ; 0.54]$} & 31.49 & .000 \\
\hline Age by relationship & $-0.31(0.16)$ & 0.73 & {$[0.54 ; 1.00]$} & 3.95 & .047 \\
\hline
\end{tabular}

Note. Gender: $1=$ male, Nationality $1=$ Austrian, 0 = non-Austrian; living in a single parent household (1) or not (0), lives alone (1) or not (0); did(1)/did not (0) attended a special school for learning disabilities; employment status of parents was dummy coded into three categories (employed, unemployed, unknown), coefficients shown indicate overall tests, none of the employment variables was significant. 


\section{Table 3}

Differences of Means and Distribution of Demographic Characteristics by Different Program Outcomes

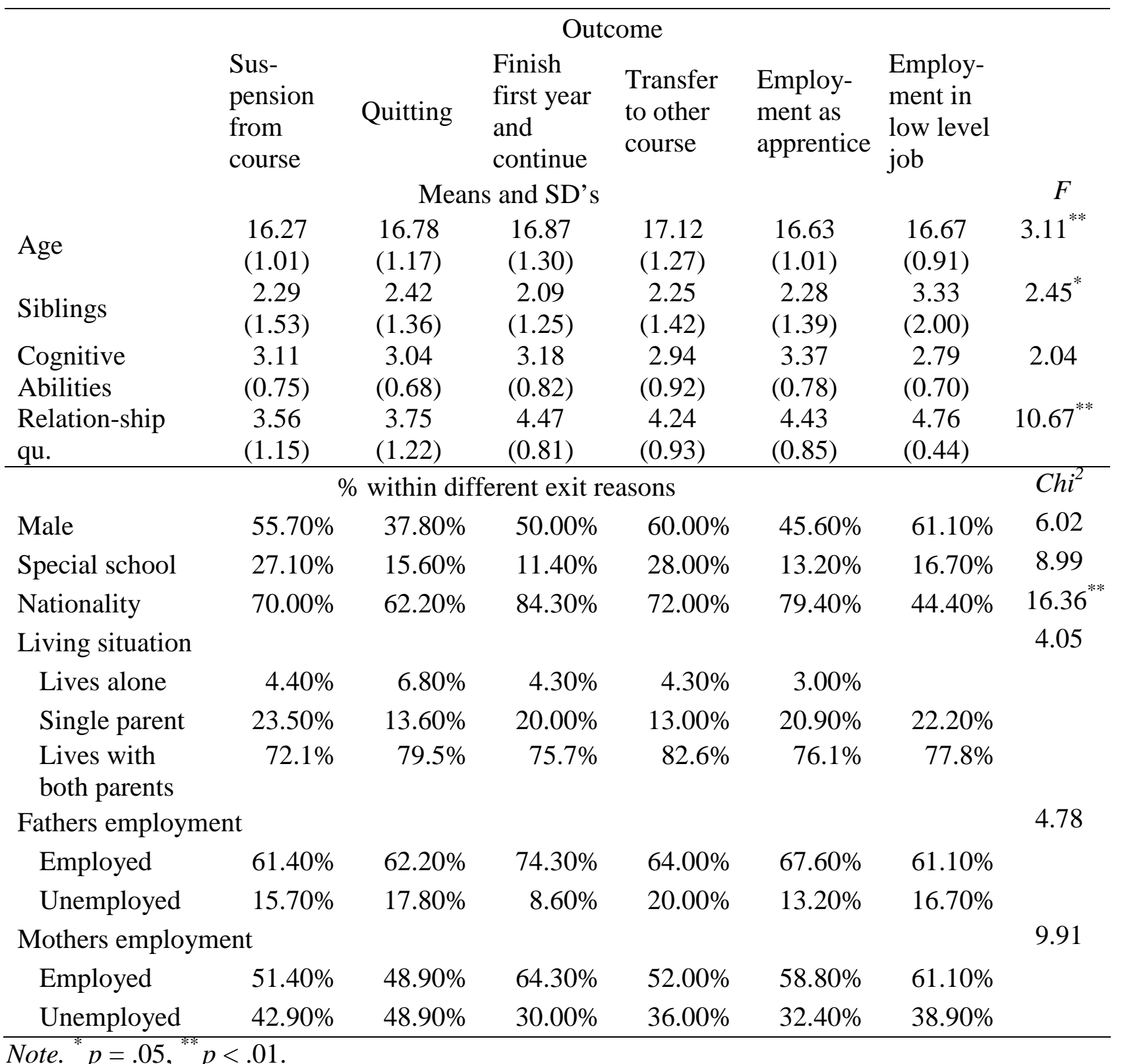




\section{Figure 1.}

Hypothesized model of the effect of aggravating factors (young age, low socio economic status) and alleviating factors (relationship with parents) during a period of being NEET on drop out of a Youth Guarantee program a year later.

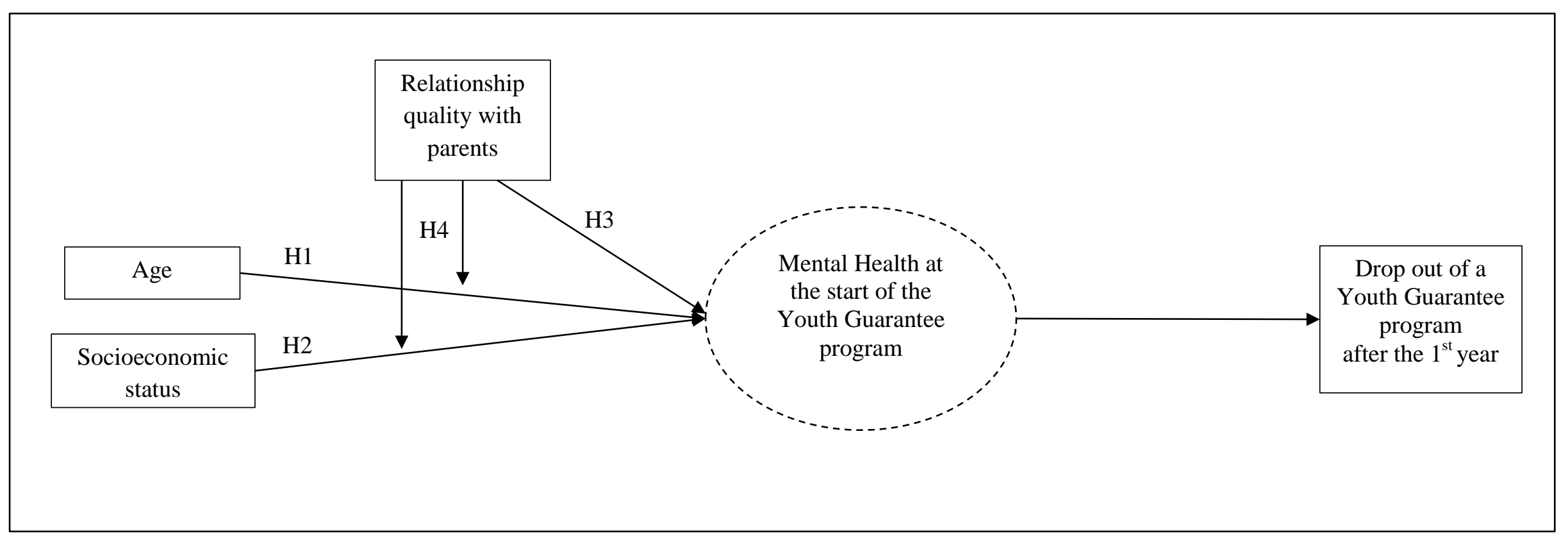

Note. Hypothesized mechanisms are in dashed shapes. 


\section{Figure 2.}

Illustration of the Interaction Effect of Relationship Quality and Age on Dropout.

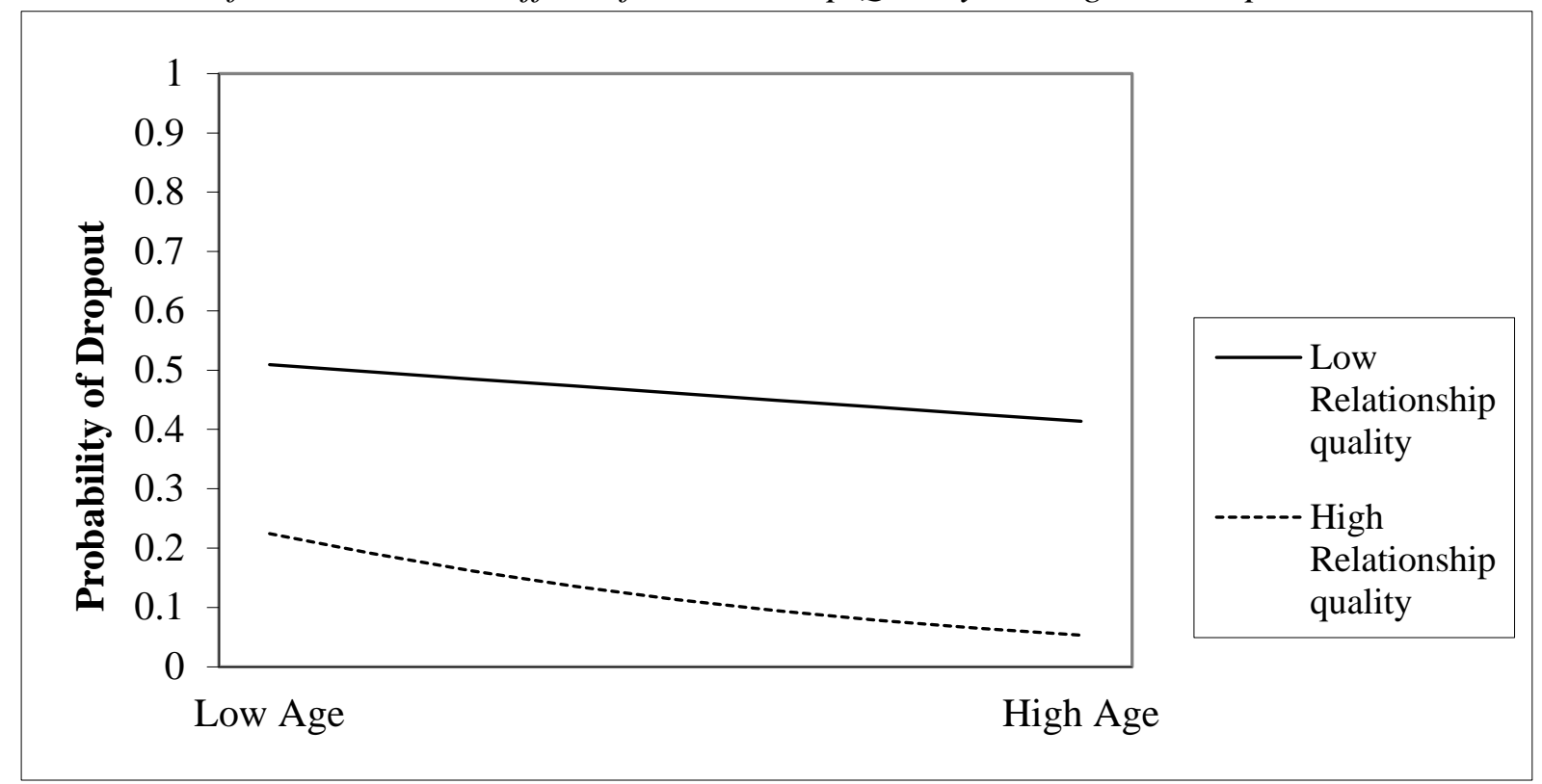

Note. Simple slope illustration of the moderating effect of relationship quality on the relationship between age and probability of drop out. Simple slopes are drawn at -1/+1 SD from the mean. 